\title{
Remembering Robert D. Terry at a Time of Change in the World of Alzheimer's Disease
}

\author{
Nickolas Terry ${ }^{\mathrm{a}}$, Alberto Masliah ${ }^{\mathrm{b}}$, Cassia Overk $^{\mathrm{c}}$ and Eliezer Masliah ${ }^{\mathrm{d}, \mathrm{e}, *}$ \\ ${ }^{a}$ Marfa, TX, USA \\ ${ }^{\mathrm{b}}$ New York, NY, USA \\ ${ }^{\mathrm{c}}$ Department of Neurosciences, University of California San Diego, La Jolla, CA, USA \\ ${ }^{\mathrm{d}}$ Division of Neuroscience and Laboratory of Neurogenetics, National Institute on Aging/NIH, Bethesda, MD, \\ USA \\ ${ }^{\mathrm{e}}$ Laboratory of Neurogenetics, National Institute on Aging/NIH, Bethesda, MD, USA
}

\begin{abstract}
Dr. Robert Terry (January 14, 1924-May 20, 2017) studied normal aging and Alzheimer's disease for more than five decades. He was at a visionary neuropathologist who trained generations of researchers in the field of neurodegenerative disorders and was always at the cutting edge of incorporating ever advancing technology into the fields of neuroscience and neuropathology. He was among the first to study plaques and tangles using electron microscopy, described the effects of aluminum on neurons, and collaborated to develop new approaches to study synaptic pathology in the context of cognitive impairment in Alzheimer's disease. Dr. Terry made indelible contributions to our understanding of Alzheimer's disease and dementia. In memory of Bob: veteran, physician-scientist, collaborator, friend, husband, and father.
\end{abstract}

Keywords: Aging, Alzheimer's disease, cognitive impairment, neurodegeneration

Robert Davis Terry, or Bob as his friends and colleagues will lovingly call him, was born in Hartford Connecticut, January 13, 1924, and passed away in Southern California, May 20, 2017. In his extraordinary 93 years of life, he witnessed and was an active participant in the profound changes that took place in the 20th century during World War II, in the fields of Medicine and Neuropathology, and in the area of neurodegenerative disorders, in particular Alzheimer's disease. After growing up in the Hartford area, he attended Williams College where he studied chemistry and biology as a pre-med student. He also demonstrated a great passion for literature, art history, and economics. However, his freshman year at

\footnotetext{
${ }^{*}$ Correspondence to: Eliezer Masliah, MD, Division of Neuroscience and Laboratory of Neurogenetics, National Institute on Aging/NIH, Bethesda, MD, USA. E-mail: emasliah@ucsd.edu.
}

Williams was quickly interrupted by the declaration of war. Three months after starting his first semester, after the attack on Pearl Harbor, he enlisted in the U.S. Army and went on active duty in June of 1943. Bob Terry went to parachute school in Fort Benning, Georgia, and served in the 3rd Platoon of the D Company, 82nd Airborne. He was eventually stationed in the Ardennes, under very cold and wet conditions and fought at the Battle of Bulge. He completed his service at the end of the war as a Private First Class. Years later, he would comment on how combat focuses the mind, strengthens certain lasting attitudes, and can teach one what effective leadership can accomplish. Later in life, one of his mentees, Dr. Larry Hansen, would say, "Dr. Terry would often look around a table and ask in his dry humor how many of these people had served in combat". Bob vividly describes his many experiences and adventures during the war in a 


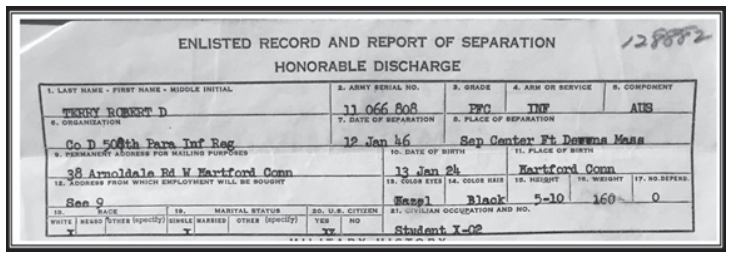

Fig. 1. Top section of Bob's Terry Honorable discharge from the Infantry as Private First Class in 1946.

remarkable autobiography where he explains, "I have written too much about the war, but I hope that at least some readers would recognize the lasting effect such experience might have, even on one who had played a minute role. I should admit here that I was a very poor combat soldier inexperienced, frightened, and badly integrated" [1].

After his honorable discharge (Fig. 1), Bob returned stateside to complete his studies at Williams. He went on to complete his medical training at Albany Medical College at a time when, as he has commented, admission to college and higher education was limited for someone of Jewish background. In January 1947, he completed a 6-month pathology study at St. Francis Hospital in Hartford Connecticut, which laid the ground for the surgical training he would receive in the Columbia University division of the Bellevue Hospital in New York City. Leaning more toward pathology, Bob went to work under Harry Zimmerman at Montefiore Hospital in the Bronx, New York (Fig. 2). It was at Montefiore where he published his first paper on adult Niemann-Pick Disease [2] and where he met and worked together with many extraordinary physicianscientists such as Asao Hirano and Nicholas Gonatas, who like Robert would be considered pillars and founders of modern neuropathology in the US (Fig. 2).

In 1952, he married Patricia Blech, a poet, scholar, and translator of medieval French literature. As they were both Francophiles, they embarked on an adventure together to France where Bob served as a postdoctoral fellow in Lillejuif, France. There he was able to train with Dr. Francoise Haguenau on a primitive RCA electron microscope. This training paved the way for him to always be at the forefront of the leading technology of his field, inspiring him for his career during the following decades as Bob was a pioneer applying electron microscopy to the studies of plaques and tangles in Alzheimer's disease [3] and describing in 1963 the fine structure of the paired helical filaments (Fig. 3) [4]. After the last 2 years of

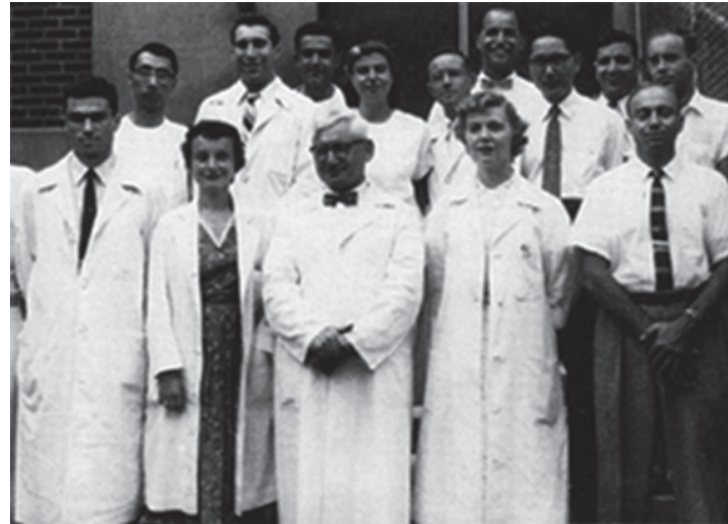

Fig. 2. The Neuropathology group at the Montefiore Hospital in the 1950s. Front row (L to R): Bob Terry, Hilda Laufer, Harry Zimmerman, and Lucretia Allen. Back row: Asao Hirano, Nick Gonatas, Kleo Siderides, and Robert Belsky.

his residency in neuropathology, largely under Martin Netsky, Bob eventually took over the day-to-day responsibilities at Montefiore Hospital until 1959, when he transferred over to the Einstein College of Medicine to head a new Division of Neuropathology. During this year, he formed a mutual research program with Saul Corey. Working with a vastly superior Siemens electron microscope, they chose Tay-Sachs disease and Alzheimer's disease for investigation. The sharp high-quality, images revealed for the first time the extraordinary structure of the abnormal lysosomes in Tay-Sachs. This legendary micrograph was displayed at the Museum of Modern Art in NY, June 20-September 11, 1967 as part of a special exhibit (Fig. 3).

Utilizing the electron microscope, Bob published seminal studies describing the fine structure of a number of pathological conditions including JacobCreutzfeldt disease [5], juvenile lipidosis [6], tin intoxication [7], colchicine encephalopathy [8], and many more. In 1969, Bob Terry received federal support to continue conducting his studies of the ultrastructure of the brain; eventually this became the first grant from the National Institute of Health (NIH) where Alzheimer's disease was named. The grant named "Cytologic Studies in Diseases of the Nervous System" (R01 NS002255) was active until 1984 when he moved to San Diego, CA. At the Einstein College of Medicine, he began to fuse technology with a new school of leadership and thought on Alzheimer's disease.

Some of his original collaborators included the late Dr. Robert Katzman, American physician, prominent 

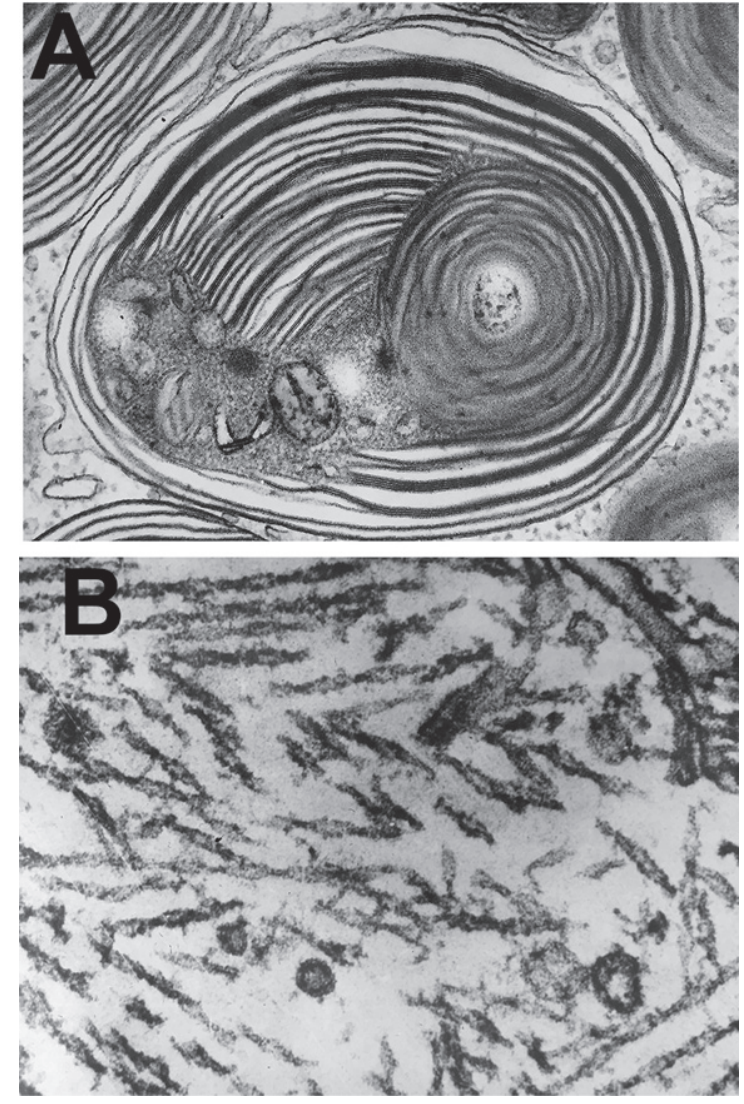

Fig. 3. Bob Terry's classical electron micrographs of (A) an abnormal lysosome in Tay Sachs Disease and (B) paired helical filaments in the neurofibrillary tangles in Alzheimer's disease.

neuroscientist, and neurologist with whom Dr. Terry forged a friendship and partnership that lasted until Dr. Katzman passing away in San Diego, California in 2008. In the early 1970s, the "two Bobs" (Fig. 4), as they were known by friends and colleagues alike, recognized for the first time that Alzheimer's disease was the most common cause of dementia in the world and a serious disorder of epidemic proportions as the population ages. First Bob Katzman [9] and then Katzman and Terry went on to publish their seminal findings [10], which signaled a new era of research in Alzheimer's disease and related dementias. At the time, these disorders were not well known and often overlooked. In 1977, the Bobs, organized the first national conference on Alzheimer's disease. Its success in capturing the attention of the scientific community and the public resulted in a flurry of research and millions in funding over the following years. They were co-founders of one of the first NIA funded Alzheimer's Disease Research Cen-

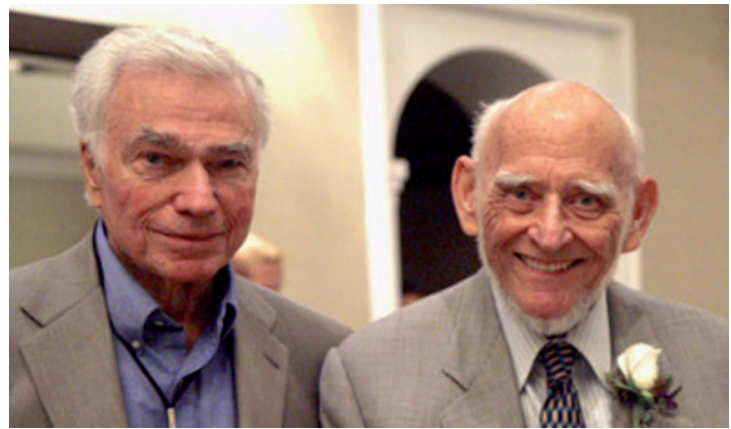

Fig. 4. The famous Bobs at their days at UCSD in the 1990s, Robert Terry (L) and Robert Katzman (R).

ters (ADRC) in the US at the University of California San Diego (UCSD) in 1985.

Thanks to their efforts, we are enjoying an extraordinary era of research on Alzheimer's disease and related dementias. We now know that these neurodegenerative disorders of the aging population affect over 5 million in the US and close to 35 million people worldwide with numbers projected to rise to 115 million by $2050[11,12]$ and that Alzheimer's disease is the $6^{\text {th }}$ cause of death in the US [13]. The US, as well as other countries, have established National plans to address this public health serious problem [14, 15]. In the US, the National Alzheimer's Project Act (NAPA) (Public Law 111-375) was signed into law in 2011. The Act defines “Alzheimer's" as Alzheimer's disease and related dementias and requests as a major goal to develop treatments for Alzheimer's disease by the year 2025. The law also calls for a National Plan and coordination with US and international bodies to fight $\mathrm{AD}$ globally (https://aspe.hhs.gov/nationalalzheimers-project-act). As a result of this, funding via the NIA/NIH in support of Alzheimer's disease research has seen a historical increase from about 600 million dollars a year in 2015 to over 2 billion dollars a year in 2019. The NIA and its sister Institutes and Centers at the National Institutes of Health, including NINDS, use the milestones and recommendations from the Alzheimer's disease summits held at the NIH in Bethesda, MD, to prioritize areas of research for support.

Bob's years at Einstein (from 1959-1984) were a time of great productivity and innovation, where he forged many long-lasting collaborations and cemented the modern school of neuropathology in the US. Among the many students and collaborators were Henry Wisniewski, Michael Shelansky, Cedric Raine, Khalid Iqbal, Nick Gonatas, Kinuko Suzuki, 

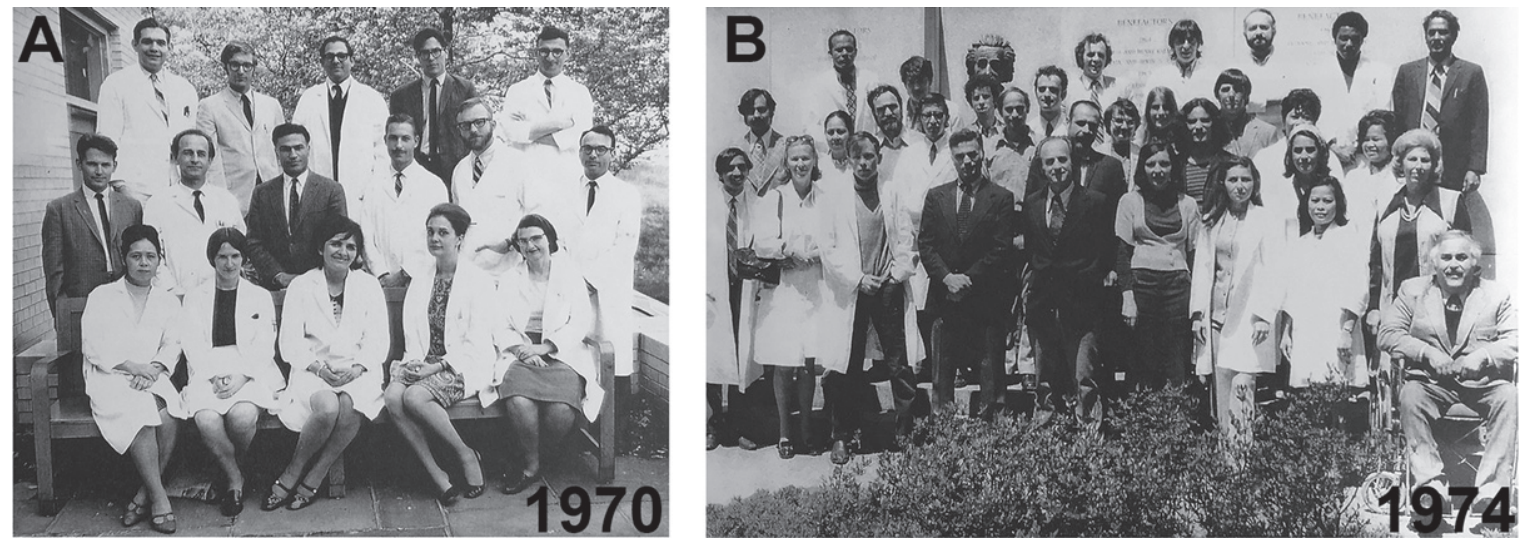

Fig. 5. Robert Terry's Neuropathology teams at the Einstein in the Bronx NY. A) In 1970, Bob Terry at the center with Henry Wisniewski to the left and Michael Shelansky in the back row. B) As the group has grown and prospered in 1974, with Bob Terry and Henry Wisniewski in the front row center and Khalid Iqbal in the far left.

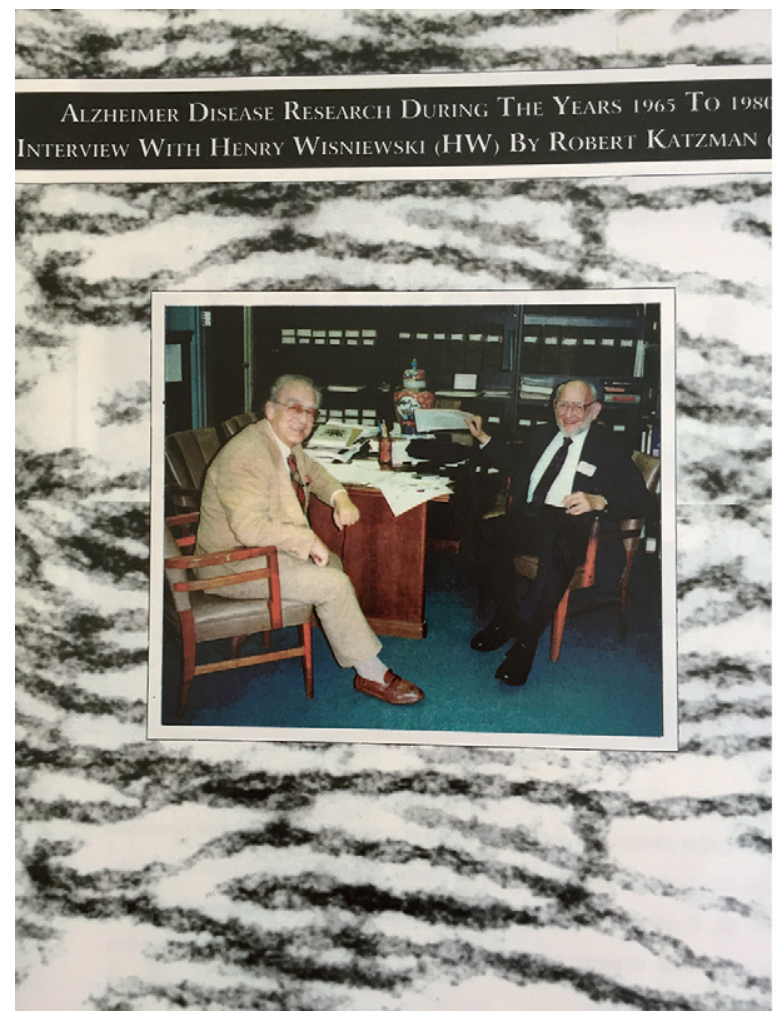

\begin{tabular}{|c|c|}
\hline \multicolumn{2}{|r|}{$\begin{array}{l}\text { ALZHEIMER DISEASE RESEARCH DURING THE YEARS } 1965 \text { TO } 1980 \\
\text { INTERVIEW WITH HENRY WISNIEWSKI (HW) BY ROBERT KATZMAN (RK) }\end{array}$} \\
\hline RK: & $\begin{array}{l}\text { As you know, Kit Bick and I are involved in this project, and we are trying to } \\
\text { reconstruct what happened sometime between the } 1950 \text { s and } 1980 \text { in terms of the } \\
\text { concepts of dementia and Alzheimer's disease, and since you were a very major } \\
\text { player in the period, we would like to hear about your own perception of how things } \\
\text { developed and your own role. We will, at some time (not right away, we are very slow) } \\
\text { send you a transcript so that you can correct any errors, and at some point, we hope } \\
\text { to publish some papers in history-of-science types of journals and a book with } \\
\text { redacted actual transcripts of what was said. }\end{array}$ \\
\hline HW: & Sure. \\
\hline RK: & That's our goal. I don't know if anybody will read it except ourselves. \\
\hline$H W:$ & No, no. People will be very interested to hear how things evolved. \\
\hline RK: & Right, I think some people will be. \\
\hline RK: & I know that you came to Bob Terry's laboratory in the mid-1960s sometime. \\
\hline HW: & $\begin{array}{l}\text { Correct. Actually, it was } \\
\text { because I was flying from Warsaw to Bob's laboratory, at Einstein, bringing with me } \\
\text { chronic aluminum-treated rabbits, which, as you know, after injection with aluminum } \\
\text { develop extensive neurofibrillary changes. You can appreciate that to get clearance } \\
\text { at the airport, it was something. On top of it, my rabbits chose to develop seizures on } \\
\text { the plane. }\end{array}$ \\
\hline
\end{tabular}

Fig. 6. Cover and front page of a transcript of an interview by Robert Katzman with Henry Wisniewski in the 1990s.

Isabel Tellez-Nagel, Peter Davies, Carol Miller, Dikran Horoupian, Mauro Dal Canto, Bernardino Ghetti, Jim Powers, Jim Goldman, and Dennis Dickson, among others [16] (Fig. 5). The late Henry Wisniewski, whom Bob convinced to join him in cold New York from equally cold Poland in November 1966, vividly describes his memories at Einstein in an unpublished interview with Bob Katzman, a copy was passed on to us (Fig. 6). This journey to New York was also the focus of one of the most lighthearted anecdotes involving Dr. Terry and a gaggle of rabbits. On his voyage from Warsaw to New York, Dr. Wisniewski brought his now infamous rabbits to Dr. Terry. These were chronic aluminum-treated 

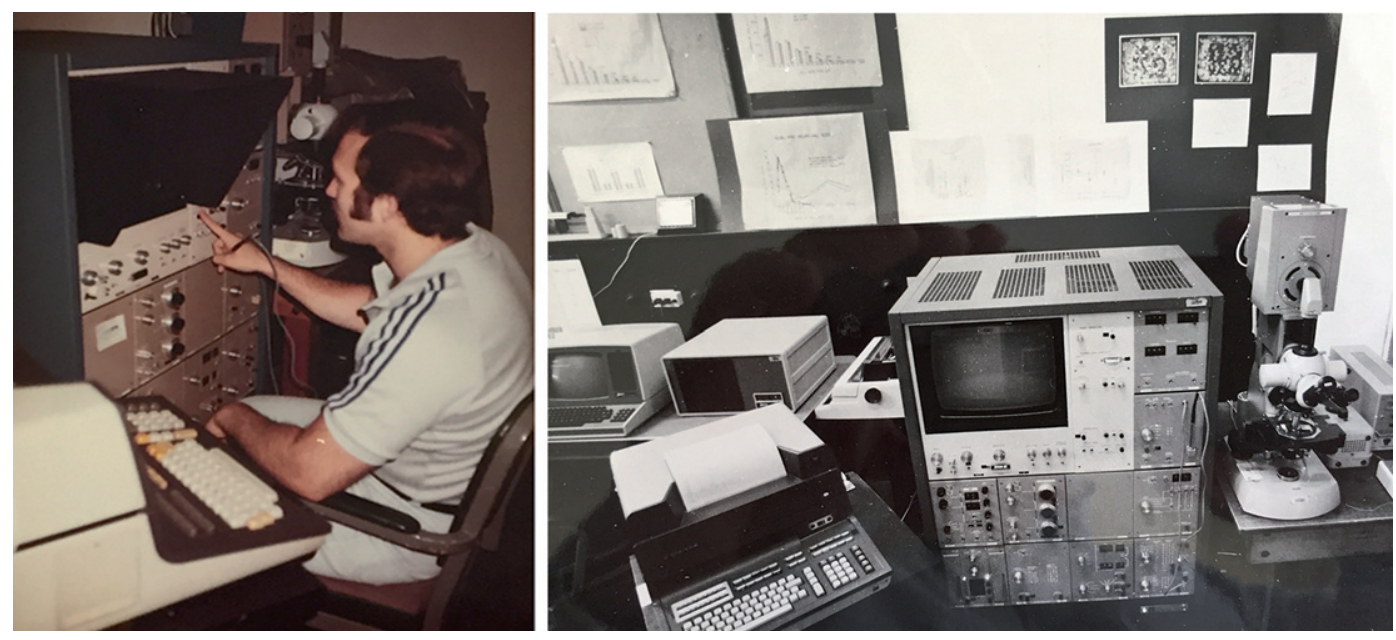

Fig. 7. The era of neuronal quantification in early 1980s. Richard DeTeresa operating the newly acquired Quantimet image analyzer at the Einstein in the Bronx.

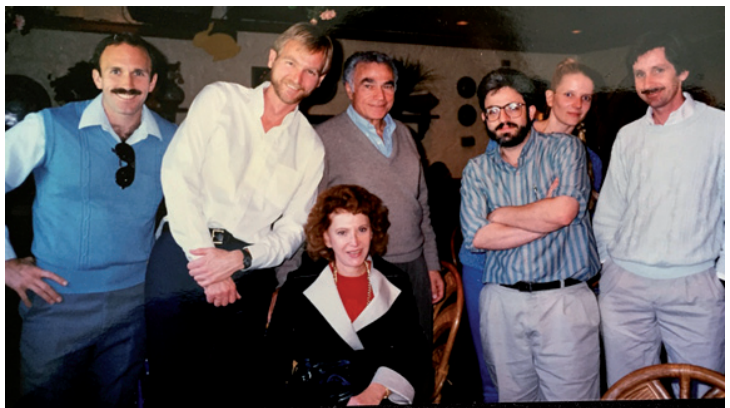

Fig. 8. Bob Terry's Neuropathology group at UCSD in 1989. (L to R) Richard DeTeresa, Larry Hansen, Ellie Michaels, Bob Terry, Eliezer Masliah, Margaret Mallory, and Michael Alford.

rabbits, which of course, experienced seizures midflight, most likely due to a lack of oxygen at a high altitude. The rabbits flew the rest of the way to New York, along with Dr. Wisniewski, in the cockpit with the pilots-who informed the health officials of their imminent, and rather grand, American arrival. Luckily, Dr. Terry greeted the wayward rabbits and their handler. He was able to convince the officials to let the rabbits come into the country, who otherwise were not so keen on allowing the rabbits out of the airport. This was not the only instance of rabbit antics at Einstein. For several years, his team at Einstein had the field to themselves; in 1969, he became the chair of Pathology. At a time when the study of Alzheimer's disease has all but been relegated to the past along with stories or Dr. Alzheimer himself, it was at Montefiore that Bob Terry brought it back to life.
He created an entire movement in the field of neurosciences uniquely integrating cutting edge technology with the study of Alzheimer's disease and its complications. His paper, together with the late Dr. Katzman, "Senile Dementia of the Alzheimer Type" from the May 1983 issue of Annals of Neurology, reinvigorated the study of Alzheimer's disease [17]. In this pivotal paper, the duo discussed the importance of differentiating Alzheimer-like dementia versus dementia caused by Down's syndrome, depression, and various other illnesses. It was also during this period that Bob led one of few laboratories in the world with an electron microscope and later using a computer-based image analysis system to quantify neurons in the brains of patients with Alzheimer's disease. At this time, Richard DeTeresa joined his group and spearheaded the research efforts. Together they analyzed for the first time the magnitude of the neurodegenerative process in Alzheimer's disease by utilizing a computer-based method to analyze neurons using the Quantimet [18] (Fig. 7). In fact, one of the many legacies that Dr. Terry leaves behind is an affinity toward the latest technology he was able to access. Indeed, those foundational days in France proved themselves paramount to Dr. Terry's future as a neuroscientist, inspiring him to continue pursuing the study of the brain with leading technology.

Eventually Bob was convinced to leave New York for the sunny shores of San Diego in 1984 in order to join Robert Katzman as a full-time investigator. Together, they went on to establish one of the first Alzheimer's Disease Research Center in the US at UCSD, which 35 years later continues to lead the 


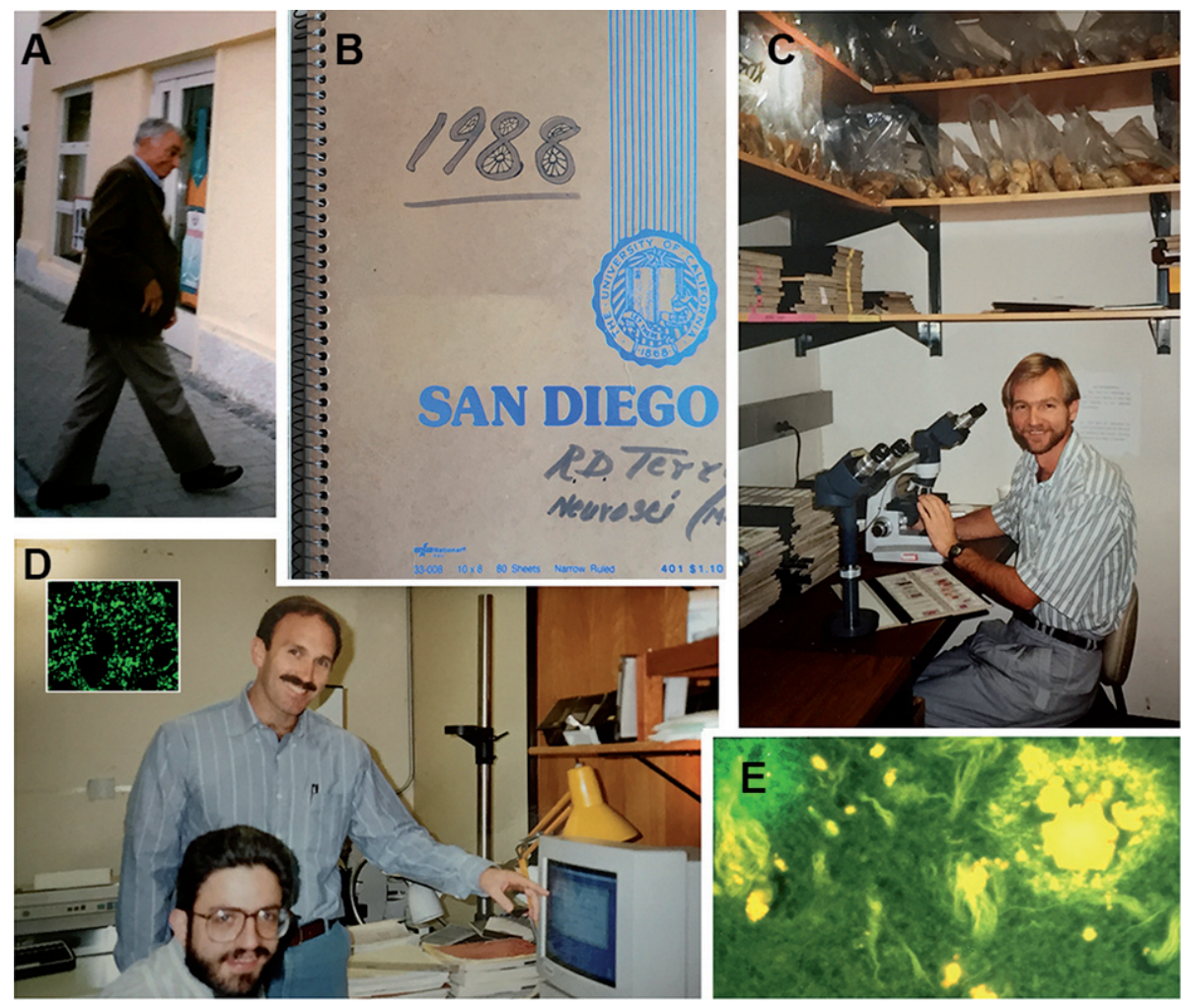

Fig. 9. The laboratory of Neuropathology at UCSD in the late 1980s. Bob arriving for a meeting (A), Bob's notebook from 1988 (B), Larry Hansen at the Alzheimer's Disease Research Center brain bank analyzing the samples (C), Richard DeTeresa and Eliezer Masliah at the digital system analyzing the first laser confocal images of synapses (synaptophysin immunolabeled) from an Alzheimer's disease brain (D), Bob Terry's classical Thioflavine S image of plaques and tangles (E).

field investigating the mechanisms of neurodegeneration in Alzheimer's disease and searching for new treatments. At UCSD, he was at the forefront of technological advancements in neurosciences. In fact, Bob in collaboration with Mark Ellisman and Eliezer Masliah and was one of the first researchers to use a laser scanning confocal microscopy to investigate and develop tridimensional maps of the synapses, tangles, and amyloid deposits in Alzheimer's disease [19-21]. They found that synaptic pathology occurs early in the pathogenesis of Alzheimer's disease and that more closely correlates with dementia compared to tau pathology and amyloid deposition [22]. The UCSD team also included Rich DeTeresa, who came with Bob to San Diego from New York, Larry Hansen, Mike Alford, and Margaret Mallory (Fig. 8); together they were able to continue pushing the frontiers of the knowledge of Alzheimer's disease.

In recognition of his extraordinary scientific contributions, Dr. Terry was the first winner of the Potamkin Prize for Research in Pick's, Alzheimer's, and related diseases in 1988. He also received the Award for
Meritorious Contributions to Neuropathology from the American Association of Neuropathologists in 1989, the Metropolitan Life Foundation Award in 1991, and he was a Fellow of the American Academy of Arts and Sciences. From 1990-1996 Dr. Terry served on the Advisory Board of the Max Planck Institute in Martinsried, Germany outside of Munich. Over 50 graduate fellows have trained in experimental and diagnostic neuropathology under his supervision.

It was also in San Diego where he continued his work on the neuropathology of Alzheimer's disease utilizing Thioflavine-S and unique array of filters with fluorescent microscopy, a simple and inexpensive method that allowed quantification of plaques and tangles simultaneously (Fig. 9). This new approach, in combination with the longitudinal clinical data collected at the ADRC at UCSD and the powerful analysis of neuronal populations with the Quantimet, revealed that in individuals with later onset of the disease or who resistant to dementia despite the amyloid pathology, might be related to a neuronal reserve [23]. 


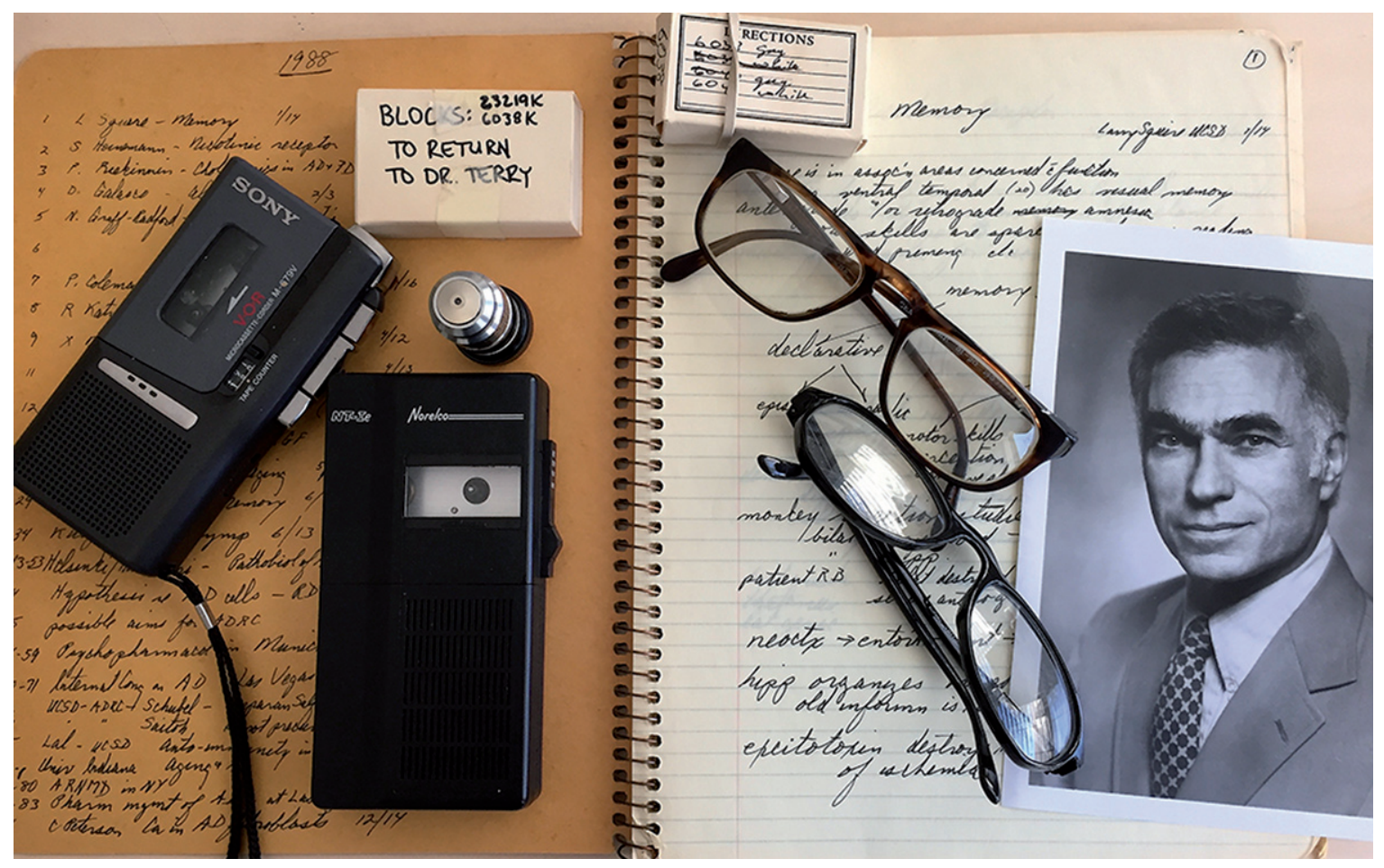

Fig. 10. Some memorabilia from Bob Terry's office at UCSD. His notebook, tape recorders, glasses, epon blocks for electron microscopy of Alzheimer's disease brain biopsies from where the images of paired helical filaments were obtained, and a picture of him at his time at the Albert Einstein College of Medicine.

Dr. Terry, together with Leon Thal, Larry Hansen, Eliezer Masliah, Rich de Teresa, and Bob Katzman, created one of the first digital databases at the UCSD ADRCs that included detailed clinical data, state of the art neuropathological parameters including neuronal and synaptic counts, and neurochemical analysis of cholinergic and non-cholinergic systems that allowed unraveling the mechanisms of cognitive impairment in Alzheimer's disease. Dr. Terry engaged in one of the earlier debates on the causes of dementia in Alzheimer's disease; was it caused by amyloid plaques or tangles? Dr. Terry asserted that, actually, neither were the cause of dementia related to the Alzheimer's disease. He said that they developed in tandem and that we needed to look closer at neuronal and synaptic loss to understand the mechanisms of dementia in the disease as evidenced on his notebook in 1988 (Fig. 10). During his tenure at UCSD, Bob championed the idea that that damage to the neuronal circuits rather than amyloid deposition was at the center of understanding the mechanisms of cognitive dysfunction in Alzheimer's disease. This is especially true these days as many of the anti-amyloid therapies have failed; a clearer understanding of the molecular mechanisms leading to synaptic damage might be the key to developing better therapies for Alzheimer's disease.

Dr. Terry researched Alzheimer's disease and normal aging for more than 35 years and is credited with many pivotal scientific advancements in the field. Some of Dr. Terry's significant contributions include being the first to study plaques and tangles using electron microscopy [24]. In addition, he was the first to describe the effects of aluminum on neurons [25]. In the late 1980s and early 1990s, in association with Eliezer Masliah who was also at UCSD, they developed novel approaches to investigate the role of synaptic pathology in the mechanisms of cognitive impairment in Alzheimer's disease [22]. The halls of the Department of Neurosciences at UCSD were often graced with a pacing Dr. Terry dictating notes into his voice recorder practicing what he referred to as "judicious intellect." $\mathrm{He}$ is still remembered today as a man always walking side by side with technology that worked tirelessly to make everlasting contributions to the study of Alzheimer's disease and its related complications (Fig. 10). From the early days of electron microscopy to confocal microscopes, 
Dr. Terry was always a leader in his field until he passed away on May 20, 2017. He lives in the collective memory of all of us, his friends, colleagues, and son, and his legacy goes on, inspiring future generations of young scientists ready to join the fight to defeat Alzheimer's disease.

His wife of 59 years, Patricia, passed away earlier on September 17, 2011. They went on many adventures together reaching the Arctic, the Himalayas, and the African plains. Dr. Terry is survived by his only child, Nick, who lives in Marfa, Texas, with his wife Maryam Amiryani, where they both work as painters.

\section{CONFLICT OF INTEREST}

Authors' disclosures available online (https:// www.j-alz.com/manuscript-disclosures/19-0518).

\section{REFERENCES}

[1] Terry RD (2011) Autobiography series. J Neuropathol Exp Neurol 70, 238-242.

[2] Terry RD, Sperry WM, Brodoff B (1954) Adult lipidosis resembling Niemann-Pick's disease. Am J Pathol 30, 263285.

[3] Terry RD, Gonatas NK, Weiss M (1964) The ultrastructure of the cerebral cortex in Alzheimer's disease. Trans Am Neurol Assoc 89, 12.

[4] Terry RD (1963) The fine structure of neurofibrillary tangles in Alzheimer's disease. J Neuropathol Exp Neurol 22, 629642.

[5] Gonatas NK, Terry RD, Weiss M (1964) Ultrastructural studies in Jacob-Creutzfeldt disease. Trans Am Neurol Assoc 89, 13-14

[6] Gonatas NK, Terry RD, Winkler R, Korey SR, Gomez CJ, Stein A (1963) A case of juvenile lipidosis: the significance of electron microscopic and biochemical observations of a cerebral biopsy. J Neuropathol Exp Neurol 22, 557-580.

[7] Aleu FP, Katzman R, Terry RD (1963) Fine structure and electrolyte analyses of cerebral edema induced by alkyl tin intoxication. J Neuropathol Exp Neurol 22, 403-413.

[8] Wisniewski H, Terry R (1967) Experimental colchicine encephalopathy. I. Introduction of neurofibrillary degeneration. Lab Invest 17, 577-587.

[9] Katzman R (1976) Editorial: The prevalence and malignancy of Alzheimer disease. A major killer. Arch Neurol 33, $217-218$
[10] Terry RD, Katzman R (1983) Senile dementia of the Alzheimer type. Ann Neurol 14, 497-506.

[11] Prince M, Bryce R, Albanese E, Wimo A, Ribeiro W, Ferri CP (2013) The global prevalence of dementia: a systematic review and metaanalysis. Alzheimers Dement 9, 63-75 e62.

[12] Alzheimer's Association (2016) 2016 Alzheimer's disease facts and figures. Alzheimers Dement 12, 459-509.

[13] Alzheimer's Association (2013) 2013 Alzheimer's disease facts and figures. Alzheimers Dement 9, 1-71.

[14] Secretary OOTA, Evaluation FPA, National Plan to Address Alzheimer's Disease, https://aspe.hhs.gov/national-plansaddress-alzheimers-disease\#2016Plan, Accessed 9/12/ 2017.

[15] Alzheimer's Disease International, National Alzheimer's and dementia plans, https://www.alz.co.uk/dementiaplans/national-plans, Accessed 9/12/2017.

[16] Powers JM (2017) Autobiography Series: From there to here. A crooked trail of families, crossroads, serendipity, and impatience. J Neuropathol Exp Neurol 76, 1058-1063

[17] Terry R, Katzman R (1983) Senile dementia of the Alzheimer type. Ann Neurol 14, 497-508.

[18] Terry R, Peck A, DeTeresa R, Schechter R, Horoupian D (1981) Some morphometric aspects of the brain in senile dementia of the Alzheimer type. Ann Neurol 10, 184-192.

[19] Masliah E, Terry R, DeTeresa R, Hansen L (1989) Immunohistochemical quantification of the synapse-related protein synaptophysin in Alzheimer disease. Neurosci Lett 103, 234-239.

[20] Masliah E, Mallory M, Hansen L, Alford M, Albright T, Terry R, Shapiro P, Sundsmo M, Saitoh T (1991) Immunoreactivity of CD45, a protein phosphotyrosine phosphatase, in Alzheimer disease. Acta Neuropathol 83, 12-20.

[21] Masliah E, Ellisman M, Carragher B, Mallory M, Young S, Hansen L, DeTeresa R, Terry R (1992) Three-dimensional analysis of the relationship between synaptic pathology and neuropil threads in Alzheimer disease. J Neuropathol Exp Neurol 51, 404-414.

[22] Terry RD, Masliah E, Salmon DP, Butters N, DeTeresa R, Hill R, Hansen LA, Katzman R (1991) Physical basis of cognitive alterations in Alzheimer's disease: synapse loss is the major correlate of cognitive impairment. Ann Neurol 30, $572-580$.

[23] Terry R, Hansen L, DeTeresa R, Davies P, Tobias H, Katzman R (1987) Senile dementia of the Alzheimer type without neocortical neurofibrillary tangle. J Neuropathol Exp Neurol 46, 262-268.

[24] Terry RD (2006) My own experience in early research on Alzheimer disease. J Alzheimers Dis 9, 117-119.

[25] Liwnicz BH, Kristensson K, Wisniewski HM, Shelanski ML, Terry RD (1974) Observations on axoplasmic transport in rabbits with aluminum-induced neurofibrillary tangles. Brain Res 80, 413-420. 